\title{
PENGARUH BUDAYA ORGANISASI KEPUASAN KERJA DAN KOMITMEN ORGANISASIONAL TERHADAP ORGANIZATIONAL CITIZENSHIP BEHAVIOR PADA KARYAWAN
}

\author{
I Nyoman Bayu Putra Mahardika ${ }^{1}$ \\ I Made Artha Wibawa ${ }^{2}$
}

\author{
${ }^{1,2}$ Fakultas Ekonomi dan Bisnis Universitas Udayana (Unud), Bali, Indonesia \\ E-mail: bayuputramahardika@gmail.com
}

\begin{abstract}
ABSTRAK
Tujuan penelitian ini adalah untuk mengetahui pengaruh budaya organisasi, kepuasan kerja dan komitmen organisasional terhadap organizational citizenship behavior. Penelitian ini dilakukan di perusahaan Focus Design Artglass Ubud. Jumlah sampel yang diambil sebanyak 67 orang karyawan, dengan menggunakan teknik sampel jenuh, khususnya simple random sampling. Pengumpulan data dilakukan melalui kuesioner. Teknik analisis yang digunakan adalah regresi linear berganda. Berdasarkan hasil analisis ditemukan bahwa budaya organisasi, kepuasan kerja dan komitmen organisasional berpengaruh positif dan signifikan terhadap organizational citizenship behavior. Semakin tinggi budaya organisasi maka OCB juga akan semakin meningkat, semakin tinggi kepuasan kerja maka semakin tinggi pula OCB, dan semakin tinggi komitmen organisasional maka semakin tinggi pula OCB pada perusahaan Focus Design Artglass Ubud.
\end{abstract}

Kata kunci: budaya organisasi, kepuasan kerja, komitmen organisasional, organizational citizenship behavior

\begin{abstract}
The purpose of this study is to determine the influence of organizational culture, job satisfaction and organizational commitment to organizational citizenship behavior. This research was conducted at the company Focus Design Artglass Ubud. The number of samples taken as many as 67 employees, using saturated sample technique, especially simple random sampling. The data were collected through questionnaires. The analysis technique used is multiple linear regression. Based on the analysis results found that organizational culture, job satisfaction and organizational commitment have positive and significant impact on organizational citizenship behavior. The higher the organizational culture OCB will also increase, the higher the job satisfaction the higher the $O C B$, and the higher the organizational commitment the higher the $O C B$ in the company Focus Design Artglass Ubud.
\end{abstract}

Keywords: organizational culture, job satisfaction, organizational commitment, organizational citizenship behavior 


\section{PENDAHULUAN}

Sumber daya manusia merupakan hal yang sangat penting dalam suatu perusahaan maupun organisasi karena keefektifan dan keberhasilan suatu perusahaan atau organisasi sangat terganutng pada kualitas dan kinerja sumber daya manusia yang ada pada organisasi. Peristiwa yang sering terjadi di dalam proses pengolahan sumber daya manusia di beberapa perusahaan adalah terkait dengan kinerja karyawan dalam perusahaan. Jika SDM perusahaan mempunyai kinerja yang baik maka berdampak langsung pada kemajuan perusahaan serta dapat mencapai tujuan yang direncanakan. Jika sumber daya manusia yang dimiliki perusahaan mempunyai kinerja yang buruk maka perusahaan akan mengalami penurunan. Davoudi (2010) menyebutkan bahwa dalam setiap perusahaan sumber daya manusia merupakan sumber daya paling vital yang dimiliki perusahaan.

Mengelola SDM yang baik, setiap pemimpin dan manajer serta bagian yang menangani SDM harus mengerti masalah dengan manajemen SDM dengan baik pula (Widodo, 2015). Memiliki karyawan yang bersedia mencurahkan segenap kemampuan demi kepentingan organisasi atau perusahaan adalah harapan bagi semua organisasi atau perusahaan. Karyawan yang dapat bertanggung jawab atas pekerjaan yang dilakukannya, perusahaan diharapkan dapat memberikan penghargaan atau pengakuan atas prestasi karyawan. Setiap perusahaan cenderung berusaha menemukan dan melaksanakan struktur organisasi yang memungkinkan sumber daya manusia yang berkualitas dan kompetetif sehingga diperoleh hasil 
I Nyoman Bayu Putra Mahardika, Pengaruh Budaya Organisasi...

kerja yang diharapkan, namun kenyataannya yang terjadi pada perusahaan sering kali tidak sesuai dengan apa yang diharapkan.

Organisasi yang sukses membutuhkan karyawan yang memiliki sifat mampu melakukan tugasnya lebih dari sekedar tugas formal mereka yang mampu memberikan kinerja melebihi harapan dari suatu organisasi atau perusahaan. Menjalankan sejumlah tugas di perusahaan dan dapat bersaing dengan kompetitor, sumber daya manusia tidak cukup hanya melakukan tugasnya masing-masing sesuai dengan job description saja, mereka harus memiliki perilaku ekstra peran yang dapat memberi pengaruh positif bagi eksistensi organisasi. Perilaku yang dapat meningkatkan produktivitas karyawan dalam perusahaan yang disebutkan dalam penelitian Harper (2015) yaitu perilaku extra-role atau disebut juga perilaku organizational citizenship behavior (OCB).

Organizational citizenship behavior (OCB) adalah perilaku dari karyawan perusahaan yang secara sukarela membantu rekan kerjanya. Dilihat dari penelitian Pourkiani et al. (2014) yang mendefinisikan OCB sebagai perilaku secara sukarela dimana bukan bagian dari tugas yang sudah ditetapkan dan tidak dihargai secara langsung. Menurut Lakshmi dan Nicholas (2015) juga menyatakan bahwa OCB merupakan suatu perilaku positif individu sebagai anggota organisasi dalam bentuk kesediaan secara sadar dan sukarela untuk bekerja dan memberikan kontribusi pada organisasi lebih daripada tuntutan yang secara formal dalam organisasi yang mendukung berfungsinya organisasi secara efektif. Menurut Rauf (2014) OCB merupakan tindakan perilaku individu yang bebas, yang tidak secara 
langsung diakui oleh sistem pemberian penghargaan dalam fungsi efektif suatu organisasi.

Stanley (2013) menyatakan bahwa OCB ditandai dengan usaha dalam bentuk apapun yang dilakukan berdasarkan kebijaksanaan pegawai yang memberikan manfaat bagi organisasi tanpa mengharapkan imbalan apapun. Contoh dari perilaku OCB adalah berinisiatif membantu rekan kerja, patuh terhadap aturan-aturan dan prosedur-prosedur di organisasi, tidak membuangbuang waktu kerja, mengajukan idea tau saran yang berguna, mampu bekerja lebih baik tanpa pengawasan pimpinan dan perilaku ini biasanya ditandai dengan spontanitas serta ketulusuan (Maria et al., 2015).

Budaya organisasi merupakan suatu sistem berbagi arti yang dilakukan para anggota yang membedakan suatu organisasi dari organisasi lain (Robbins dan Judge, 2015:355). Arifin (2015) menyatakan bahwa budaya organisasi adalah semua keyakinan, perasaan, perilaku dan simbol-simbol yang mencirikan suatu organisasi. Miharty (2013) mendefinisikan bahwa budaya organisasi mengacu pada pola asumsi dasar bersama dan kelompok telah dapat memecahkan masalah yang diadopsi dari eskternal dan integrasi internal yang telah bekerja cukup baik untuk dipertimbangkan. Menurut Xiaoming dan Junchen (2012) budaya organisasi sebagai pola pemecahan masalah internal dan eksternal yang diterapkan secara konsisten bagi suatu kelompok atau organisasi.

Fungsi utama dari budaya organisasi adalah sebagai batas pembeda terhadap lingkungan, organisasi maupun kelompok lain dan sebagai mekanisme kontrol dalam memandu dan membentuk sikap serta perilaku karyawan (Supartha, 
I Nyoman Bayu Putra Mahardika, Pengaruh Budaya Organisasi...

2008:27). Tampak budaya organisasi mampu memberikan dampak positif bagi OCB disuatu perusahaan. Oemar (2013) menyatakan bahwa semakin positif pegawai dalam menilai budaya organisasi dan semakin terlibat ia dalam organisasi yang ada di instansinya, maka kecenderungan organizational citizenship behavior (OCB) akan meningkat pula.

Kepuasan kerja merupakan respon individu terhadap pengalamannya dalam bekerja (Giaque et al., 2014). Kepuasan kerja merupakan tingkat kepuasan yang dirasakan karyawan terkait dengan pekerjaan karyawan (Puangyoykeaw dan Nishide, 2015). Penelitian yang luas terhadap kepuasan kerja menunjukkan bahwa faktor-faktor pribadi seperti kebutuhan dan aspirasi individu menentukan kepuasan kerja ini, bersama dengan kelompok dan faktor organisasi seperti hubungan antara rekan kerja dan supervisor dan kondisi kerja, kebijakan kerja dan kompensasi (Griffin dan Moorhead, 2014:74).

Tampak logis untuk mengasumsikan kepuasan kerja seharusnya menjadi suatu penentu utama dari OCB. Pekerja yang puas seharusnya akan kelihatan berbicara positif mengenai organisasinya, membantu rekan kerjanya dan melebihi ekpetasi normal dalam pekerjaannya yang mungkin karena mereka ingin membalas pengalaman positifnya. Kepuasan kerja berkorelasi dengan OCB dilihat dari orang-orang yang puas dengan pekerjaannya lebih mungkin terlibat dalam OCB (Robbins dan Judge, 2015:53). Fitrianasari dkk. (2013) menyatakan bahwa kepuasan kerja berpengaruh secara langsung terhadap Organizational Citizenship Behavior teruji. Hal ini bisa dilihat dari persepsi kepuasan kerja terkait dengan perasaan senang pada beberapa aspek pokok pekerjaan yang mendapat tanggapan 
positif akan menjadi faktor pendorong semakin tingginya organizational citizenship behavior.

Penelitian Merry Ristiana (2013) yang menyatakan kepuasan kerja merupakan determinan penting yang mendorong seseorang memperlihatkan perilaku organizational citizenship behavior (OCB), disebabkan individu-individu yang mendapatkan kepuasan dalam pekerjaannya, akan cenderung memaknai pekerjaan dan tugas-tugas yang ia laksanakan dengan penuh tanggungjawab dan dedikasi. Penelitian Wijaya dan Sutanto (2014) menyatakan kepuasan kerja karyawan berpengaruh positif dan signifikan terhadap organizational citizenship behavior. Hal ini berarti jika kepuasan kerja karyawan semakin tinggi akan dapat meningkatkan organizational citizenship behavior di PT XYZ Surabaya secara nyata.

Komitmen organisasional dipandang sebagai suatu orientasi nilai terhadap organisasi yang menunjukkan pemikiran individu dan mengutamakan pekerjaan dan organisasinya (Tania dan Sutanto, 2013). Menurut Dewi (2013) karyawan yang memiliki komitmen organisasional adalah karyawan yang terlibat aktif di dalam organisasi serta aktif mencapai tujuan organisasi. Komitmen terhadap organisasi akan membuat karyawan setia pada organisasi dan bekerja dengan baik untuk kepentingan organisasi (Chamdam, 2013).

Astuti et al. (2013) menyatakan komitmen organisasional adalah salah satu faktor yang mempengaruhi keberhasilan organisasi dalam menghadapi lingkungan yang lebih kompleks, karyawan yang memiliki komitmen organisasional yang kuat akan mengidentifikasi bisnis mereka dengan bisnis organisasi, semakin serius 
I Nyoman Bayu Putra Mahardika, Pengaruh Budaya Organisasi...

karyawan di tempat kerja serta memiliki loyalitas dan kasih sayang dapat mengejar tujuan organisasi. Komitmen organisasi merupakan tingkat dimana pekerja mengidentifikasi sebuah organisasi, tujuan dan harapannya untuk tetap menjadi anggota (Robbins dan Judge, 2015:G-6).

Komitmen merupakan salah satu variabel yang telah banyak diketahui memiliki kaitan yang erat dengan Organizational Citizenship Behavior (OCB). Karyawan yang memiliki komitmen organisasional yang tinggi akan melakukan tidak hanya tugas-tugas yang telah menjadi kewajibannya, tetapi dengan sukarela akan mengerjakan hal-hal yang dapat digolongkan sebagai usaha-usaha ekstra (extra effort) (Organ, 2003:2-3). Penelitian Devi dan Adnyani (2015) mengemukakan bahwa komitmen karyawan yang besar akan lebih sering berbicara secara positif tentang perusahaannya, membantu individu lain dan jauh melebihi harapan normal dalam pekerjaan mereka, selain itu karyawan melakukan pekerjaan dilandasi keinginan sendiri atau tanpa paksaan. Penelitian yang dilakukan oleh Sani (2013) yang melibatkan 74 karyawan PT Bank Syariah Malang juga menemukan bahwa komitmen organisasional berpengaruh positif terhadap OCB.

Penelitian ini dilakukan di salah satu pabrik manufaktur Focus Design Artglass yang bergerak di bidang manufaktur yang berletak di daerah Ubud. Focus Design Artglass ini salah satu pabrik kerajinan kaca yang sudah dikenal dikalangan masyarakat Ubud bahkan wisatawan mancanegara pun banyak yang berdatangan kesana untuk mencari kerajinan-kerajinan kaca yang unik sebagai oleh-oleh. Peran karyawan di pabrik ini harus diperhatikan kualitasnya kerjanya, 
seperti yang kita ketahui untuk meningkatkan produktivitas produk di Focus Design Artglass ini dibutuhkan tenaga kerja yang memiliki sifat OCB. Organizational Citizenship Behavior memiliki peranan bagi Focus Design Artglass untuk dapat memperbaiki sisi buruk karyawan yang tidak mau bekerjasama antar karyawan mengingat pabrik kerajinan kaca ini memerlukan kerjasama yang baik antar karyawan dalam menyelesaikan pekerjaannya. Seperti karyawan yang lagi kosong bisa membantu karyawan lain yang sedang dalam kesususahan dalam pekerjaannya yang sudah dikejar waktu. Riset awal yang dilakukan peneliti terhadap beberapa karyawan di Focus Design Artglass Ubud dapat dilihat bahwa peran tenaga kerja dalam membantu rekan kerja yang mengalami masalah masih kurang. Hal ini dapat dilihat pada Tabel 1:

Tabel 1.

Permasalahan beberapa karyawan yang bekerja di Focus Design Artglass Ubud

\begin{tabular}{ccc}
\hline No & Jumlah Orang & \multicolumn{1}{c}{ Masalah dari Karyawan } \\
\hline $\mathbf{1}$ & 6 & $\begin{array}{l}\text { Karyawan tidak mau menolong rekan kerjanya karena } \\
\text { karyawan tersebut merasa memiliki tugasnya masing-masing } \\
\text { dan juga kurangnya karyawan tersebut dalam berinteraksi } \\
\text { dengan sesama rekan kerja }\end{array}$ \\
$\mathbf{2}$ & 2 & $\begin{array}{l}\text { Karyawan sering malas-malasan saat bekerja } \\
\text { Karyawan sering mengeluh jika diberikan tugas tambahan } \\
\text { oleh pimpinan } \\
\text { Karyawan sering mengabaiakan atau tidak tertarik dengan } \\
\text { kegiatan yang dilaksanakan oleh perusahaan }\end{array}$ \\
$\mathbf{4}$ & 3 & \\
\hline Jumlah & 15 &
\end{tabular}

Tabel 1 menunjukkan bahwa terdapat beberapa masalah dalam karyawan Focus Design Artglass yang bisa dikatakan memiliki tingkat OCB masih cukup rendah. Tabel diatas menunjukkan 6 dari 15 orang tidak mau menolong rekan kerjanya karena karyawan tersebut merasa memiliki tugasnya masing-masing dan juga kurangnya karyawan tersebut dalam berinteraksi dengan sesama rekan 
I Nyoman Bayu Putra Mahardika, Pengaruh Budaya Organisasi...

kerjanya, 2 dari 15 orang sering malas-malasan dalam melakukan tugasnya di perusahaan, 3 dari 15 orang sering mengeluh jika diberikan tugas tambahan dari pimpinan perusahaan dan 4 dari 15 orang sering mengabaikan atau tidak tertarik dengan kegiatan atau event yang dilaksanakan oleh perusahaan. Rendahnya tingkat OCB ini dapat mengakibatkan dampak negatif bagi perusahaan seperti dapat mengurangi produktifitas rekan kerja, dapat mengurangi produktifitas manajerial, dan dapat mengurangi efisiensi penggunaan sumber daya organisasionalnya.

Untuk mengatasai persoalan yang terungkap diatas, yang mana karyawan dihadapkan oleh sejumlah tugas dan tanggung jawab yang besar serta tuntunan akan peran profesinya, dan dilain pihak kurangnya sifat karyawan dalam membantu sesama rekan kerjanya secara sukarela, maka dari itu sangat dibutuhkan perilaku ekstra peran dari karyawan pabrik yang dikenal sebagai Organizational Citizenship Behavior (OCB).

Berdasarkan latar belakang, maka rumusan masalah penelitian adalah sebagai berikut: 1) Bagaimana pengaruh budaya organisasi terhadap organizational citizenship behavior pada karyawan Focus Design Artglass Ubud? 2) Bagaimana pengaruh kepuasan kerja terhadap organizational citizenship behavior pada karyawan Focus Design Artglass Ubud? 3) Bagaimana pengaruh komitmen organisasional terhadap organizational citizenship behavior pada karyawan Focus Design Artglass Ubud?

Berdasarkan latar belakang dan rumusan masalah diatas, maka yang menjadi tujuan dari penelitian ini adalah: 1) Untuk menjelaskan pengaruh budaya 
organisasi terhadap organizational citizenship behavior pada karyawan Focus Design Artglass Ubud. 2) Untuk menjelaskan pengaruh kepuasan kerja terhadap organizational citizenship behavior pada karyawan Focus Design Artglass Ubud. 3) Untuk menjelaskan pengaruh komitmen organisasional terhadap organizational citizenship behavior pada karyawan Focus Design Artglass Ubud.

Berdasarkan tujuan penelitian yang telah diuraikan, adapun kegunaan dari penelitian ini adalah: 1) Manfaat Teoritis: Hasil penelitian ini diharapkan dapat memperluas wawasan dan pengetahuan serta bukti empiris mengenai pengaruh budaya organisasi, kepuasan kerja dan komitmen oganisasional terhadap organizational citizenship behavior. Penelitian ini juga diharapkan akan dapat menjadi referensi bagi peneliti yang akan melakukan penelitian terkait. 2) Manfaat Praktis: Hasil penelitian ini diharapkan dapat dijadikan sebagai bahan pertimbangan dan masukan terhadap Focus Design Artglass Ubud berkaitan dengan pengaruh budaya organisasi, kepuasan kerja dan komitmen organisasional terhadap organizational citizenship behavior. Sehingga Focus Design Artglass Ubud bisa lebih menekankan hal-hal yang sifatnya bisa meningkatkan budaya dalam sebuah organisasi, kepuasan kerja dari karyawan dan komitmen organisasi dalam perusahaan yang nantinya dipercaya dapat meningkatkan organizational citizenship behavior dalam perusahaan.

Teori yang melandasi penelitian ini adalah teori pertukaran sosial (Social Exchange Theory). Fung et al. (2012) menyatakan bahwa teori pertukaran sosial merupakan pandangan karyawan ketika mereka telah diperlakukan dengan baik oleh organisasi, mereka akan cenderung untuk bersikap dan berperilaku lebih 
poditif terhadap organisasi. Setiap individu selalu akan berusaha untuk membalas budi terhadap siapapun yang telah memberikannya keuntungan. Liden et al. (2003) menyatakan bahwa kecenderungan individu membalas sumberdaya dan dukungan yang diterimanya dari orang lain adalah sangat kuat, yang mengarah pada fenomena seperti norma timbal balik, dan diekspresikan dengan meningkatkan komitmennya pada organisasi.

Teori pertukaran sosial menjelaskan bagaimana menjaga keseimbangan pertukaran sosial antara karyawan dan organisasi. Teori pertukaran sosial Konovsky dan Pugh (1994) sering digunakan guna menjelaskan mengapa karyawan melakukan organizational citizenship behavior. Mereka berpendapat bahwa ketika karyawan merasa puas dengan pekerjaannya, mereka akan membalasanya. Balasan dari karyawan tersebut termasuk perasaan yang menjadi bagian (sense of belonging) dari organisasi yang menyebabkan perilaku seperti organizational citizenship behavior.

\subsubsection{Organizational Citizenship Behavior}

Pourkiani et al. (2014) mendefinisikan OCB sebagai perilaku secara sukarela dimana bukan bagian dari tugas yang sudah ditetapkan dan tidak dihargai secara langsung. Menurut Lakshmi dan Nicholas (2015) menyatakan bahwa OCB merupakan suatu perilaku positif individu sebagai anggota organisasi dalam bentuk kesediaan secara sadar dan sukarela untuk bekerja dan memberikan kontribusi pada organisasi lebih daripada tuntutan yang secara formal dalam organisasi yang mendukung berfungsinya organisasi secara efektif. Menurut Rauf (2014) OCB merupakan tindakan perilaku individu yang bebas, yang tidak secara 
langsung diakui oleh sistem pemberian penghargaan dalam fungsi efektif suatu organisasi.

Stanley (2013) menyatakan bahwa OCB ditandai dengan usaha dalam bentuk apapun yang dilakukan berdasarkan kebijaksanaan pegawai yang memberikan manfaat bagi organisasi tanpa mengharapkan imbalan apapun. Contoh dari perilaku OCB adalah berinisiatif membantu rekan kerja, patuh terhadap aturan-aturan dan prosedur-prosedur di organisasi, tidak membuangbuang waktu kerja, mengajukan idea tau saran yang berguna, mampu bekerja lebih baik tanpa pengawasan pimpinan dan perilaku ini biasanya ditandai dengan spontanitas serta ketulusuan (Maria et al., 2015).

Robbins dan Judge (2015:355) menyatakan budaya organisasi merupakan suatu sistem berbagi arti yang dilakukan para anggota yang membedakan suatu organisasi dari organisasi lain. Menurut Belias dan Koustelios (2014) budaya organisasi merupakan pola asumsi dasar untuk mengatasi masalah eksternal maupun integrasi internal dan yang telah bekerja cukup baik untuk dianggap sah. Arifin (2015) menyatakan bahwa budaya organisasi adalah semua keyakinan, perasaan, perilaku dan simbol-simbol yang mencirikan suatu organisasi. Penelitian Erna Setyawanti (2012) juga mengatakan bahwa budaya organisasi memberikan pengaruh signifikan dan positif terhadap OCB pegawai PT. PLN (Persero) Area Pelayanan dan Jaringan (APJ) Purwokerto. Menurut Maulani dkk. (2015) hasil penelitiannya diketahui terdapat pengaruh yang signifikan antara budaya organisasi terhadap organizational citizenship behavior (OCB). Penelitian Cahyono dkk. (2016) menyatakan bahwa hasil pengujian budaya organisasi 
menunjukkan pengaruh yang signifikan terhadap organizational citizenship behavior (OCB) tenaga medis pada RSU Kaliwates Jember.

Miharty (2013) mendefinisikan bahwa budaya organisasi mengacu pada pola asumsi dasar bersama dan kelompok telah dapat memecahkan masalah yang diadopsi dari eskternal dan integrasi internal yang telah bekerja cukup baiik untuk dipertimbangkan. Menurut Xiaoming dan Junchen (2012) budaya organisasi sebagai pola pemecahan masalah internal dan eksternal yang diterapkan secara konsisten bagi suatu kelompok atau organisasi.

Menurut Giaque et al. (2014) kepuasan kerja merupakan respon individu terhadap pengalamannya dalam bekerja. Kepuasan kerja merupakan tingkat kepuasan yang dirasakan karyawan terkait dengan pekerjaan karyawan (Puangyoykeaw dan Nishide, 2015). Penelitian yang luas terhadap kepuasan kerja menunjukkan bahwa faktor-faktor pribadi seperti kebutuhan dan aspirasi individu menentukan kepuasan kerja ini, bersama dengan kelompok dan faktor organisasi seperti hubungan antara rekan kerja dan supervisor dan kondisi kerja, kebijakan kerja dan kompensasi (Griffin dan Moorhead, 2014:74).

Kepuasan kerja merupakan suatu perasaan positif tentang pekerjaan, yang dihasilkan dari suatu evaluasi dari karakteristik-karakteristiknya (Robbins dan Judge, 2015:46). Menurut Sari dkk. (2015) mengatakan bahwa kepuasan kerja adalah sikap positif karyawan terhadap pekerjannya yang timbul dari implementasi yang sesuai dengan harapan. Menurut Tania dan Sutanto (2013) komitmen organisasional dipandang sebagai suatu orientasi nilai terhadap organisasi yang menunjukkan pemikiran individu dan mengutamakan pekerjaan 
dan organisasinya. Menurut Dewi (2013) karyawan yang memiliki komitmen organisasional adalah karyawan yang terlibat aktif di dalam organisasi serta aktif mencapai tujuan organisasi. Komitmen terhadap organisasi akan membuat karyawan setia pada organisasi dan bekerja dengan baik untuk kepentingan organisasi (Chamdam, 2013).

Astuti et al. (2013) menyatakan komitmen organisasional adalah salah satu faktor yang mempengaruhi keberhasilan organisasi dalam menghadapi lingkungan yang lebih kompleks, karyawan yang memiliki komitmen organisasional yang kuat akan mengidentifikasi bisnis mereka dengan bisnis organisasi, semakin serius karyawan di tempat kerja serta memiliki loyalitas dan kasih sayang dapat mengejar tujuan organisasi. Komitmen organisasi merupakan tingkat dimana pekerja mengidentifikasi sebuah organisasi, tujuan dan harapannya untuk tetap menjadi anggota (Robbins dan Judge, 2015:G-6).

Menurut penelitian Oemar (2013) menyatakan bahwa semakin positif pegawai dalam menilai budaya organisasi dan semakin terlibat ia dalam organisasi yang ada di instansinya, maka kecenderungan organizational citizenship behavior (OCB) akan meningkat pula. Penelitian Wijaya dan Yuniawan (2017) juga menyatakan bahwa budaya organisasi berpengaruh positif dan signifikan terhadap organizational citizenship behavior (OCB). Hal ini dapat dilihat dari semakin baik atau kuat budaya organisasi akan semakin meningkatkan organizational citizenship behavior karyawan pada PT. Pos Indonesia Processing Center Semarang. Penelitian Erna Setyawanti (2012) juga mengatakan bahwa budaya organisasi memberikan pengaruh signifikan dan positif terhadap OCB pegawai 
I Nyoman Bayu Putra Mahardika, Pengaruh Budaya Organisasi...

PT. PLN (Persero) Area Pelayanan dan Jaringan (APJ) Purwokerto. Menurut Maulani dkk. (2015) hasil penelitiannya diketahui terdapat pengaruh yang signifikan antara budaya organisasi terhadap organizational citizenship behavior (OCB). Penelitian Cahyono dkk. (2016) menyatakan bahwa hasil pengujian budaya organisasi menunjukkan pengaruh yang signifikan terhadap organizational citizenship behavior (OCB) tenaga medis pada RSU Kaliwates Jember.

$\mathrm{H}_{1}$ : Budaya Organisasi berpengaruh positif dan Signifikan Terhadap Organizational Citizenship Behavior (OCB)

Menurut penelitian Fitrianasari dkk. (2013) yang menyatakan bahwa kepuasan kerja berpengaruh secara langsung terhadap Organizational Citizenship Behavior (OCB) teruji. Hal ini bisa dilihat dari persepsi kepuasan kerja terkait dengan perasaan senang pada beberapa aspek pokok pekerjaan yang mendapat tanggapan positif akan menjadi faktor pendorong semakin kuatnya organizational citizenship behavior (OCB). Penelitian Merry Ristiana (2013) yang menyatakan kepuasan kerja merupakan determinan penting yang mendorong seseorang memperlihatkan perilaku organizational citizenship behavior (OCB), disebabkan karena individu-individu yang mendapatkan kepuasan dalam pekerjaannya, akan cenderung memaknai pekerjaan dan tugas-tugas yang ia laksanakan dengan penuh tanggungjawab dan dedikasi. Penelitian Wijaya dan Sutanto (2014) menyatakan kepuasan kerja karyawan berpengaruh positif dan signifikan terhadap organizational citizenship behavior. Hal ini berarti jika kepuasan kerja karyawan semakin tinggi akan dapat meningkatkan organizational citizenship behavior di 
PT XYZ Surabaya secara nyata. Widyanto dkk. (2013) dalam penelitiannya kepuasan kerja berpengaruh secara positif dan signifikan tehadap OCB karyawan cleaning service ISS Surabaya. Hal ini berarti semakin baik kepuasan kerja maka semakin tinggi OCB karyawan cleaning service ISS Surabaya. Sesen dan Basim (2012) membuktikan bahwa adanya pengaruh positif signifikan kepuasan kerja terhadap OCB pada guru sekolah menengah di Turkey. Penelitian ini menyebutkan kepuasan kerja selain dapat mempengaruhi organizational citizenship behavior, juga dapat dipengaruhi oleh organizational citizenship behavior sendiri.

$\mathrm{H}_{2}$ : Kepuasan Kerja berpengaruh positif dan Signifikan Terhadap Organizational Citizenship Behavior (OCB)

Penelitian yang dilakukan Rini dkk. (2013) menunjukkan bahwa komitmen organisasi memiliki pengaruh positif signifikan terhadap OCB. Ratnaningsih (2013) dalam penelitiannya menemukan bahwa komitmen memberikan pengaruh yang positif terhadap OCB. Komitmen karyawan yang besar akan lebih sering berbicara secara positif tentang perusahaannya, membantu individu lain dan jauh melebihi harapan normal dalam pekerjaan mereka, selain itu karyawan melakukan pekerjaan dilandasi keinginan sendiri atau tanpa paksaan (Devi dan Adnyani, 2015). Penelitian yang dilakukan oleh Sani (2013) yang melibatkan 74 karyawan PT Bank Syariah Malang menemukan bahwa komitmen organisasional berpengaruh positif terhadap OCB. Menurut penelitian Rahmawati (2013) ditemukan bahwa komitmen organisasi memberikan pengaruh yang positif terhadap OCB. 
I Nyoman Bayu Putra Mahardika, Pengaruh Budaya Organisasi...

$\mathrm{H}_{3}$ : Komitmen Organisasional berpengaruh positif dan Signifikan Terhadap Organizational Citizenship Behavior (OCB)

\section{METODE PENELITIAN}

Pada penelitian ini, peneliti mengambil lokasi penelitian di Focus Design Artglass Ubud yang berletak di Jalan Raya Mas, Ubud, Gianyar, Bali. Alasan yang melatarbelakangi peneliti melakukan penelitian di Focus Design Artglass Ubud karena peneliti melihat ada permasalahan yang meyangkut OCB di pabrik ini.

Penelitian ini menggunakan pendekatan kuantitatif yang bersifat asosiatif untuk meneliti data yang bersifat statistik serta menguji suatu hipotesis dengan kuisioner sebagai instrumen yang dipakai. Hal ini dikarenakan ada hubungan antara variabel bebas budaya organisasi $\left(\mathrm{X}_{1}\right)$, kepuasan kerja $\left(\mathrm{X}_{2}\right)$, dan komitmen organisasional $\left(\mathrm{X}_{3}\right)$ dengan variabel terikat yaitu organizational citizenship behavior (OCB) (Y).

Pada Penelitian ini, jumlah populasi dalam penelitian ini adalah 67 Karyawan Focus Design Artglass Ubud. Teknik pengambilan sampel dalam penelitian ini adalah teknik sampel jenuh yang memberikan peluang yang sama bagi setiap unsur populasi untuk dipilih menjadi anggota sampel. Yang meliputi simple random sampling karena pengambilan sampel anggota populasi dilakukan secara acak tanpa memperhatikan strata yang ada dalam populasi tersebut.

Teknik analisis data yang digunakan dalam penelitian ini adalah metode regresi linier berganda untuk mengetahui pengaruh Budaya Organisasi $\left(\mathrm{X}_{1}\right)$, Kepuasan Kerja $\left(\mathrm{X}_{2}\right)$, Komitmen Organisasional $\left(\mathrm{X}_{3}\right)$ dan Organizational Citizenship Behavior (OCB) (Y). Metode ini diuji menggunakan sistem komputer 
berupa spss versi 21 . Pengaruh variabel independen terhadap variabel dependen diuji dengan tingkat kepercayaan $95 \%$ atau $\alpha=5 \%$. Model regresi yang digunakan adalah sebagai berikut:

$$
Y=\alpha+\beta_{1} X_{1}+\beta_{2} X_{2}+\beta_{3} X_{3} \varepsilon
$$

Keterangan:

$$
\begin{array}{ll}
\mathrm{Y} & =\text { Organizational Citizenship Behavior (OCB) } \\
\mathrm{X}_{1} & =\text { Budaya Organisasi } \\
\mathrm{X}_{2} & =\text { Kepuasan Kerja } \\
\mathrm{X}_{3} & =\text { Komitmen Organisasional } \\
\alpha & =\text { Konstanta } \\
\beta_{1} & =\text { Koefisien regresi Budaya Organisasi } \\
\beta_{2} & =\text { Koefisien regresi Kepuasan Kerja } \\
\beta_{3} & =\text { Koefisien regresi Komitmen Organisasi } \\
\varepsilon & =\text { eror }
\end{array}
$$

\begin{tabular}{|c|c|c|c|c|}
\hline No & Karakteristik & Klasifikasi & $\begin{array}{l}\text { Jumlah } \\
\text { Orang }\end{array}$ & Persentase (\%) \\
\hline \multirow{4}{*}{1} & \multirow{3}{*}{ Usia (Tahun) } & $21-30$ & 26 & 38,8 \\
\hline & & $31-40$ & 30 & 44,8 \\
\hline & & $>40$ & 11 & 16,4 \\
\hline & Jumlah & & 67 & 100 \\
\hline \multirow{3}{*}{2} & \multirow{2}{*}{ Jenis Kelamin } & Laki -Laki & 46 & 68,7 \\
\hline & & Perempuan & 21 & 31,3 \\
\hline & Jumlah & & 67 & 100 \\
\hline \multirow{3}{*}{3} & \multirow{2}{*}{ Pendidikan Terakahir } & SMA & 42 & 62,7 \\
\hline & & Sarjana & 25 & 37,3 \\
\hline & Jumlah & & 67 & 100 \\
\hline \multirow{4}{*}{4} & & $<1$ Tahun & 25 & 37,3 \\
\hline & Lama Bekerja & 1 - 3 Tahun & 30 & 44,8 \\
\hline & & $>3$ Tahun & 12 & 17,9 \\
\hline & Jumlah & & 67 & 100 \\
\hline
\end{tabular}

\section{HASIL DAN PEMBAHASAN}

Tabel 2.

Karakteristik Responden pada Focus Design Artglass Ubud Tahun 2018

Sumber: Data diolah, 2018 
I Nyoman Bayu Putra Mahardika, Pengaruh Budaya Organisasi...

Karakteristik responden yang diteliti dalam penelitian ini meliputi : usia, jenis kelamin, pendidikan terakhir, lama bekerja. Ringkasan mengenai karakteristik responden dapat dilihat pada tabel diatas. Berdasarkan Tabel 2 dapat dilihat bahwa responden yang berusia antara 21-30 tahun berjumlah 26 responden atau berkisar 38,8 persen. Responden yang berusia antara 31 - 40 tahun berjumlah 30 responden atau berkisar 44,8 persen. Responden yang berusia lebih dari 40 tahun berjumlah 11 responden atau berkisar 16,4 persen. Hal ini menunjukkan bahwa karyawan Focus Design Artglass Ubud didominasi oleh usia 31-40 tahun dikarenakan perekrutan karyawan tidak melihat usia dari seseorang. Penerimaan karyawan di perusahaan ini lebih memprioritaskan penduduk lokal yang tinggal di daerah Ubud. Penduduk lokal yang berusia 21-30 tahun cenderung lebih memilih bekerja di Hotel atau Restoran.

Berdasarkan Tabel 2 dapat dilihat bahwa responden yang berjenis kelamin laki-laki berjumlah 46 responden atau berkisar 68,7 persen dan responden yang berjenis kelamin perempuan berjumlah 21 responden atau berkisar 31,3 persen. Hal ini menunjukkan bahwa karyawan Focus Design Artglass Ubud didomiasi oleh laki-laki dikarenakan pekerjaan di perusahaan ini cukup berat dan sering dikerjakan oleh laki-laki.

Berdasarkan Tabel 2 dapat dilihat bahwa responden yang pendidikan terakhir SMA berjumlah 42 responden atau berkisar 62,7 persen dan responden yang pendidikan terakhir sarjana berjumlah 25 responden atau berkisar 37,3 responden. Hal ini menunjukkan bahwa karyawan Focus Design Artgass Ubud didominasi oleh pendidikan terakhir SMA dikarenakan penduduk lokal tidak 
memiiki biaya untuk melanjutkan pendidikan ke jenjang yang lebih tinggi, maka dari itu perusahaan ini tidak memandang tingkat pendidikan seseorang.

Berdasarkan Tabel 2 dapat dilihat bahwa responden yang lama bekerja kurang dari 1 tahun berjumlah 25 responden atau berkisar 37,3 persen. Responden yang lama bekerja antara $1-3$ tahun berjumlah 30 responden atau berkisar 44,8 persen. Responden yang lama bekerja lebih dari 3 tahun berjumlah 12 responden atau berkisar 17,9 persen. Hal ini menunjukkan bahwa karyawan Focus Design Artglass Ubud didominasi oleh karyawan yang lama bekerjanya sekisar 1-3 tahun dikarenakan perusahaan memiliki cabang baru 3 tahun yang lalu dan perusahaan tersebut membutuhkan tenaga lebih untuk membantu di cabang lain tersebut.

Tabel 3.

Hasil Uji Analisis Regresi Linier Berganda

\begin{tabular}{|c|c|c|c|c|c|}
\hline \multirow[t]{2}{*}{ Model } & \multicolumn{2}{|c|}{ Unstandardized Coefficients } & \multirow{2}{*}{$\begin{array}{c}\text { Standardized } \\
\text { Coefficients } \\
\text { Beta }\end{array}$} & \multirow[t]{2}{*}{$T$} & \multirow[t]{2}{*}{ Sig } \\
\hline & B & Std. Error & & & \\
\hline (Constant) & 12,252 & 4,699 & & 2,607 & 0,011 \\
\hline Budaya Organisasi & 0,849 & 0,339 & 0,279 & 2,508 & 0,015 \\
\hline Kepuasan Kerja & 0,837 & 0,362 & 0,258 & 2,315 & 0,024 \\
\hline Komitmen & 0,651 & 0,189 & 0,379 & 3,450 & 0,001 \\
\hline Organisasional & & & & & \\
\hline $\mathrm{R}$ & 0,860 & & & & \\
\hline $\mathrm{R}^{2}$ & 0,672 & & & & \\
\hline Adjusted $\mathrm{R}^{2}$ & 0,656 & & & & \\
\hline
\end{tabular}

Berdasarkan Tabel 3 nilai signifikan uji t sebesar 0,015. Hasil analisis pengaruh Budaya Organisasi terhadap Organizational Citizenship Behavior diperoleh nilai Sig. $\mathrm{t}$ sebesar 0,015 dengan nilai koefisien beta 0,279. Nilai Sig. $\mathrm{t}$ $0,015<0,05$ mengindikasikan bahwa $\mathrm{H}_{0}$ ditolak dan $\mathrm{H}_{1}$ diterima. Hasil ini mempunyai arti bahwa Budaya Organisasi berpengaruh positif dan signifikan terhadap Organizational Citizenship Behavior. Hasil analisis menyatakan bahwa 
I Nyoman Bayu Putra Mahardika, Pengaruh Budaya Organisasi...

budaya organisasi berpengaruh pada organizational citizenship behavior. Hasil ini sesuai dengan hipotesis satu $\left(\mathrm{H}_{1}\right)$ yang menyatakan bahwa Budaya Organisasi berpengaruh positif dan signifikan terhadap Organizational Citizenship Behavior. Hasil yang signifikan ini disebabkan oleh karyawan akan berorientasi terhadap hasil yang akan dicapai, karyawan akan selalu berorientasi kepada semua kepentingan anggotanya dan karyawan selalu agresif dalam bekerja di perusahaan.

Hasil ini sejalan dengan hasil penelitian yang dilakukan oleh Oemar (2013) yang menyatakan bahwa semakin positif pegawai dalam menilai budaya organisasi dan semakin terlibat ia dalam organisasi yang ada di instansinya, maka kecenderungan organizational citizenship behavior (OCB) akan meningkat pula. Penelitian Wijaya dan Yuniawan (2017) juga menyatakan bahwa budaya organisasi berpengaruh positif dan signifikan terhadap organizational citizenship behavior (OCB). Hal ini dapat dilihat dari semakin baik atau tinggi budaya organisasi akan semakin meningkatkan organizational citizenship behavior karyawan pada PT. Pos Indonesia Processing Center Semarang.

Penelitian Erna Setyawanti (2012) juga mengatakan bahwa budaya organisasi memberikan pengaruh signifikan dan positif terhadap OCB pegawai PT. PLN (Persero) Area Pelayanan dan Jaringan (APJ) Purwokerto. Menurut Maulani dkk. (2015) hasil penelitiannya diketahui terdapat pengaruh yang signifikan antara budaya organisasi terhadap organizational citizenship behavior (OCB). Penelitian Cahyono dkk. (2016) menyatakan bahwa hasil pengujian budaya organisasi menunjukkan pengaruh yang signifikan terhadap 
organizational citizenship behavior (OCB) tenaga medis pada RSU Kaliwates Jember.

Berdasarkan Tabel 3 nilai signifikan uji t sebesar 0,024. Hasil analisis pengaruh Kepuasan Kerja terhadap Organizational Citizenship Behavior diperoleh nilai Sig. $\mathrm{t}$ sebesar 0,024 dengan nilai koefisien beta 0,258. Nilai Sig. $t$ $0,024<0,05$ mengindikasikan bahwa $\mathrm{H}_{0}$ ditolak dan $\mathrm{H}_{1}$ diterima. Hasil ini mempunyai arti bahwa Kepuasan Kerja berpengaruh positif dan signifikan terhadap Organizational Citizenship Behavior. Hasil analisis menyatakan bahwa kepuasan kerja berpengaruh pada organizational citizenship behavior. Hasil ini sesuai dengan hipotesis dua (H2) yang menyatakan bahwa Kepuasan Kerja berpengaruh positif dan signifikan terhadap Organizational Citizenship Behavior. Hasil yang signifikan ini disebabkan oleh karyawan puas dengan adanya kesempatan promosi, karyawan puas dengan adanya bantuan dari atasannya dan karyawan senang dengan hubungan yang baik dengan rekan kerjanya.

Hal ini sejalan dengan penelitian yang dilakukan Fitrianasari dkk. (2013) yang menyatakan bahwa kepuasan kerja berpengaruh secara langsung terhadap Organizational Citizenship Behavior (OCB) teruji. Hal ini bisa dilihat dari persepsi kepuasan kerja terkait dengan perasaan senang pada beberapa aspek pokok pekerjaan yang mendapat tanggapan positif akan menjadi faktor pendorong semakin kuatnya organizational citizenship behavior (OCB). Penelitian Merry Ristiana (2013) yang menyatakan kepuasan kerja merupakan determinan penting yang mendorong seseorang memperlihatkan perilaku organizational citizenship behavior (OCB), disebabkan karena individu-individu yang mendapatkan 
I Nyoman Bayu Putra Mahardika, Pengaruh Budaya Organisasi...

kepuasan dalam pekerjaannya, akan cenderung memaknai pekerjaan dan tugastugas yang ia laksanakan dengan penuh tanggungjawab dan dedikasi.

Penelitian Wijaya dan Sutanto (2014) menyatakan kepuasan kerja karyawan berpengaruh positif dan signifikan terhadap organizational citizenship behavior. Hal ini berarti jika kepuasan kerja karyawan semakin tinggi akan dapat meningkatkan organizational citizenship behavior di PT XYZ Surabaya secara nyata. Widyanto dkk. (2013) dalam penelitiannya kepuasan kerja berpengaruh secara positif dan signifikan tehadap OCB karyawan cleaning service ISS Surabaya. Hal ini berarti semakin baik kepuasan kerja maka semakin tinggi OCB karyawan cleaning service ISS Surabaya. Sesen dan Basim (2012) membuktikan bahwa adanya pengaruh positif signifikan kepuasan kerja terhadap OCB pada guru sekolah menengah di Turkey. Penelitian ini menyebutkan kepuasan kerja selain dapat mempengaruhi organizational citizenship behavior, juga dapat dipengaruhi oleh organizational citizenship behavior sendiri.

Berdasarkan Tabel 3 nilai signifikan uji t sebesar 0,001. Hasil analisis pengaruh Komitmen Organisasional terhadap Organizational Citizenship Behavior diperoleh nilai Sig. t sebesar 0,001 dengan nilai koefisien beta 0,379. Nilai Sig. t 0,001 $<0,05$ mengindikasikan bahwa $\mathrm{H}_{0}$ ditolak dan $\mathrm{H}_{1}$ diterima. Hasil ini mempunyai arti bahwa Komitmen Organisasional berpengaruh positif dan signifikan terhadap Organizational Citizenship Behavior. Hasil analisis menyatakan bahwa komitmen organisasional berpengaruh pada organizational citizenship behavior. Hasil ini sesuai dengan hipotesis tiga $\left(\mathrm{H}_{3}\right)$ yang menyatakan bahwa Komitmen Organisasional berpengaruh positif dan signifikan terhadap 
Organizational Citizenship Behavior. Hasil yang signifikan ini disebabkan oleh karyawan bangga bekerja di perusahaan ini, karyawan menganggap bekerja di perusahaan ini merupakan suatu kebutuhan, karyawan merasa bekerja di perusahaan ini merupakan kesempatan yang baik, karyawan bersedia dilibatkan dalam kegiatan kerja demi kepentingan perusahaan dan karyawan tidak akan meninggalkan perusahaan karena masih memiliki tanggung jawab.

Hal ini sejalan dengan penelitian yang dilakukan Rini dkk. (2013) menunjukkan bahwa komitmen organisasi memiliki pengaruh positif signifikan terhadap OCB. Ratnaningsih (2013) dalam penelitiannya menemukan bahwa komitmen memberikan pengaruh yang positif terhadap OCB. Komitmen karyawan yang besar akan lebih sering berbicara secara positif tentang perusahaannya, membantu individu lain dan jauh melebihi harapan normal dalam pekerjaan mereka, selain itu karyawan melakukan pekerjaan dilandasi keinginan sendiri atau tanpa paksaan (Devi dan Adnyani, 2015). Penelitian yang dilakukan oleh Sani (2013) yang melibatkan 74 karyawan PT Bank Syariah Malang menemukan bahwa komitmen organisasional berpengaruh positif terhadap OCB. Menurut penelitian Rahmawati (2013) ditemukan bahwa komitmen organisasi memberikan pengaruh yang positif terhadap OCB.

Hasil penelitian ini memiliki implikasi teoritis dan praktis. Secara teoritis, hasil penelitian ini menunjukkan bahwa budaya organisasi, kepuasan kerja dan komitmen organisasional berpengaruh positif dan signifikan terhadap organizational citizenship behavior. Dengan demikian, hasil penelitian ini memberi dukungan empiris dan dapat dinyatakan memperkuat hasil-hasil studi 
terdahulu. Secara praktis, penelitian ini diharapkan dapat memberikan manfaat bagi pemimpin dan karyawan Focus Design Artglass Ubud. Manajemen dan karyawan diharapkan dapat menerima budaya asing masuk ke lingkungan organisasi dan tidak membedakan budaya satu dengan budaya lain, sehingga meningkatkan prilaku OCB pada karyawan di perusahaan. Manajemen dan karyawan terbukti bisa membantu sesama rekan kerjanya karena perilaku itu dapat membuat kinerja karyawan lebih cepat selesai dan lebih efisien di perusahaan. Selain itu, manajemen dan karyawan juga meningkatkan komitmen dalam organisasinya, karena dengan meningkatkan komitmen dalam perusahaan dapat menciptakan kerjasama yang baik terhadap rekan kerja yang dapat meningkat periaku OCB pada karyawan di perusahaan.

\section{SIMPULAN DAN SARAN}

Berdasarkan pembahasan yang telah diuraikan pada bab sebelumnya, maka diperoleh simpulan sebagai berikut Budaya organisasi memiliki pengaruh positif dan signifikan terhadap organisasi citizenship behavior. Hal ini menunjukan bahwa ketika budaya organisasi diterapkan dengan sangat baik didalam organisasi maka akan meningkatkan sikap OCB pada karyawan dalam organisasi. Kepuasan kerja memiliki pengaruh positif dan signifikan terhadap organizational citizenship behavior. Semakin tinggi kepuasan kerja yang dimiliki karyawan terhadap organisasi maka akan meningkatan sikap OCB pada karyawan dalam organisasi. Komitmen organisasional memiliki pengaruh positif dan siginifikan terhadap organizational citizenship behavior. Hal ini menunjukan bahwa semakin besar 
komitmen organisasional karyawan pada perusahaan maka akan meningkatkan sikap OCB pada karyawan dalam organisasi.

Saran yang dapat diberikan berdasarkan hasil penelitian dan pembahasan adalah sebagai berikut Secara teoritis untuk meningkatkan organizational citizenship behavior, hal yang harus diperhatikan adalah budaya organisasi, kepuasan kerja dan komitmen organisasional. Variabel komitmen organisasional menjadi salah satu variabel yang sangat penting untuk diperhatikan karena memiliki nilai standar koefisien paling tinggi. Variabel yang harus diperhatikan dalam meningkatkan organizational citizenship behavior adalah komitmen organisasional di bandingkan dengan variabel budaya organisasi dan kepuasan kerja. Saran secara praktis terhadap Focus Design Artglass Ubud untuk meningkatkan OCB dari karyawannya adalah dengan memperhatikan altruism atau perilaku menolong (karyawan bersedia membantu rekan kerja di area lain dan Karyawan bersedia membantu dan melatih karyawan baru), memperhatikan conscientiousness atau kesungguhan dalam bekerja (karyawan tidak menambah waktu istirahat), memperhatikan sportsmanship atau toleransi yang tinggi (karyawan dapat menoleransi sikap karyawan lain walaupun tidak menyenangkan dan karyawan dapat mentoleransi permintaan staf), inovasi memperhitungkan resiko, memberi perhatian pada setiap masalah secara detail, pekerjaan itu sendiri, gaji, komitmen afektif (karyawan senang menghabiskan karir di organisasi dan organisasi memiliki makna mendalam bagi karyawan), komitmen normatif (karyawan berkeinginan untuk menghabiskan sisa karirnya pada organisasi tempat ia bekerja) karena hal tersebut dapat meningkatkan sifat OCB dari karyawan 
I Nyoman Bayu Putra Mahardika, Pengaruh Budaya Organisasi...

perusahaan. Saran bagi penelitian selanjutnya, penelitian ini hanya sebatas meneliti mengenai budaya organisasi, kepuasan kerja dan komitmen organisasional terhadap organizational citizenship behavior. Peneliti selanjutnya diharapkan untuk menambah variabel lain, seperti : motivasi dan iklim organisasi, karena peneliti ini hanya memandang organizational citizenship behavior yang dipengaruhi oleh budaya organisasi, kepuasan kerja dan komitmen organisasional. Peneliti selanjutnya juga diharapkan dapat mengganti metode yang dipakai dengan metode yang lain, seperti : teknik analisis jalur (path), karena peneliti hanya menggunakan teknik regresi linier berganda pada penelitian ini. Peneliti selanjutnya juga diharapkan dapat mengambil sampel di luar lingkungan industri manufaktur, seperti : Perhotelan, Sekolah, dan Rumah Sakit.

\section{REFRENSI}

Arifin, H. Muhammad. (2015). The Influence of Competence, Motivation, and Organizational Culture to High School Teacher Job Satisfaction and Performance. International Education Studies. Vol. 8(1). Pp: 38-45.

Astuti Endang Stiti, Kusdi Raharjo and Djamhur Hamid. (2013). The Effect Of Empowerment Of The Organizational Commitment And The Job Satisfaction Of The Employees Of The National Electricity Company (Ltd). Asian Transactions On Basic \& Applied Science, (ATBAS ISSN : 2221-4291) Volume 03 Issue 04, pp : 62-86

Belias, Dimitrios., and Athanasios Koustelios. (2014). Organizational Culture and Job Satisfaction: A Review in University of Thessaly, Karyes, 42100, Trikala, Greece. International Review of Management and Marketing. 4(2), pp: 132-149.

Cahyono, Bayu Chandra., Raden Andi Sularso., Sumani. (2016). Pengaruh Budaya Organisasi , Kepemimpinan Dan Stres Kerja Terhadap Organizational Citizenship Behavior (OCB) Dengan Kepuasan Kerja Sebagai Variabel Intervening Pada Tenaga Medis Rsu Kaliwates Kabupaten Jember. Jurnal Relasi STEI Mandala. Vol 23. Pp: 400-413. 
Chamdan Purnama. (2013). Influence Analysis of Organizational Culture Organizational Commitment Job and Satisfaction OrganizationalCitizenship Behavior (OCB) Toward Improved Organizational Performance. International Journal of Business, Humanities and Technology. 3(5): pp: 86-100.

Davoudi, Seyed. (2010). Organizational Commitment and Extra Role Behavior: A Survey in Iran's Insurance Industry. Journal of Business Systems, Governance and Ethics, 7 (1), pp: 66-75.

Devi, Windu Sari dan Dewi Adnyani. (2015). Pengaruh Kepuasan Kerja Karyawan terhadap Komitmen Organisasional dan Organizational Citizenship Behavior (OCB) pada PT. Maharani Prema. E-Jurnal Manajemen Unud, 4(12), hh: 4105-4134.

Dewi, K.S. (2013).Pengaruh Gaya Kepemimpinan Transformasional Terhadap Kepuasan Kerja Karyawan Dan Komitmen Organisasi Pada Pt. Kpm. Jurnal Manajemen, Strategi Bisnis, dan Kewirausahan, 7(2). Hal: 75-90.

Erna Setyawati. (2012). Pengaruh Tingkat Kecerdasan Emosi Dan Sikap Pada Budaya Organisasi Terhadap Organizational Citizenship Behavior (OCB) Pegawai Pt. Pln (Persero) Area Pelayanan Dan Jaringan (Apj) Purwokerto. Jurnal Probisnis. 5(2).hh: 42-59.

Fitrianasari,Dini., Umar Nimran., Hamidah Nayati Utami. (2013). Pengaruh Kompensasi Dan Kepuasan Kerja Terhadap Organizational Citizenship Behavior (OCB) Dan Kinerja Karyawan. Jurnal Profit. 7(1). Pp: 12-24.

Fung, N.S., Ahmad, A., and Omar, Z. (2012). Work-Family Enrichment: It's Mediating Role in The Relationship between Dispositional Factors and Job Satisfaction. International Journal of Academic Research in Business and Social Science. Vol. 2 no. 11. Pp 11-88.

Giaque David, Fabien Resenterra dan Michael Siggen. (2014). Antecedents of Job Satisfaction, Organizational Commitment and Stress in a Public Hospital: a P-E Fit Perspective. Public Organization Review, 14; pp: 201-228

Griffin, Ricky W. dan Gregory Moorhead. (2014). Organizational Behavior: Managing People and Organizations. Eleventh Edition, United States of America: South-Western.

Harper, Pamela J. (2015). Exploring Forms of Organizational Citizenship Behaviors (OCB): Antecedents and Outcame. Journal of Management and Marketing Research, Vol. 18 pp: 1-16.

Konovsky, M.A and Pugh. S.D. (1994). Citizenship Behavior and Social Exchange. Academy of Management Journal. 37(3). 
Lakshmi Putu Aninditha Veera dan Nicholas Simarmata. (2015). Hubungan antara Iklim Organisasi dengan Perilaku Kewargaan Organisasi Pada Karyawan di Perusahaan Ritel. Jurnal Psikologi Udayana. 2(1), hh:25-37.

Liden, R.C. Wayne, S.J., Kraimer, M.L., and Sparrowe. (2003). The Dual Commitments of Contingent Workers: An Examination of Contingent's Commitment to The Agency and The Organization. Journal of Organizational Behavior, 24. 605-625.

Luthans, Fred. (2006). Perilaku Organisasi. Edisi 10, Yogyakarta: ANDI.

Maria. Zayas Ortiz., Ernesto. Rosalio Eulalia., Marquez Pablo. Colon Gruneiro. (2015). Relationship between organizational commitments and organizational citizenship behavior in a sample of private banking employees". International Journal of Sociology and Social Policy, 35(1): h: $91-100$

Maulani, Venty Hertina., Widiartanto., dan Reni Shinta Dewi. (2015). Pengaruh Budaya Organisasi Dan Komitmen Organisasi Terhadap Kinerja Karyawan Melalui Organizational Citizenship Behavior (OCB) Sebagai Variabel Intervening. Jurnal Ilmu Administrasi Bisnis. 4(3).hh: 224-235.

Merry Ristiana M. (2013). Pengaruh Komitmen Organisasi Dan Kepuasan Kerja Terhadap Organizational Citizenship Behavior (OCB) Dan Kinerja Karyawan Rumah Sakit Bhayangkara Trijata Denpasar. DIE, Jurnal Ilmu Ekonomi \& Manajemen. 9(1). hh: 56-70.

Miharty. (2013). The Influence of Organizational Culture on Job Satisfaction towards Improving the Quality of Edication in University of Riau. Asian Social Science. Vol 9(12). Pp:1-9.

Organ, D.W. (2003). Organizational citizenship behavior : The good soldier syndrome. Lexington, MA : Lexington Books.

Organ. (2003). Organizational Citizenship Behavior: The Good Soldier Syndrome, Lexington, Ma: Lexington Books.

Pourkiani Masoud, Farokhian Abdolmajid and Gheisari Farhad. (2014). Explaining The Relationship Between Organizational Climate, Organizational Commitment and Organizational Citizenship Behavior Among Emppployees of Khuzestan Gas Company. Indian Journal of Fundamental and Applied Life Sciences. 4(3), pp. 282-290.

Puangyykeaw, Kevalin dan Yuko Nishide. (2015). Organizational Commitment and Turnover Intention in Low-Skilled Immigrant Workers in Thailand: An Empirical Assessment of Need Satisfaction, Job Satisfaction and 
Overall Life Satisfactions Factors. International Journal Of Business and Management, 10(5); pp: 98-112.

Rahmawati. (2013). Pengaruh Kepuasan Kerja dan Komitmen terhadap Organizational Citizenship Behavior (OCB). Media Mahardika. 11(2).hh.113-138.

Ratnaningsih, S.Y. (2013).Pengaruh kepuasan kerja dan komitmen organisasi terhadap organizational citizenship behavior (OCB). Media Mahardika.11(2),h: 113-138.

Rauf F.H. Abdul. (2014). Perception of Organizational Justice as a Predictor of Organizational Citizenship Behavior: An Empirical Study at Schools in Sri Lanka. European Journal of Business and Management. 6(12), pp: 124130.

Rini, Dyah P., Rusdarti dan Suparjo. (2013). Pengaruh Komitmen Organisasi, Kepuasan Kerja dan Budaya Organisasi Terhadap Organizatinal Citizenship Behaviour (OCB) (Studi pada PT. Plasa Simpanglima Semarang). Jurnal Ilmiah Dinamika Ekonomi dan Bisnis, 1(1), h: 2337608269.

Robbins, Stephen P. dan Judge, Timothy A. (2015). Perilaku Organisasi Edisi 16. Jakarta Selatan. Salemba Empat. G-6.

Robbins, Stephen P. dan Timothy A. Judge, (2015), Perilaku Organisasi, Edisi 16, Jakarta: Salemba Empat, 46-47.

Robbins, Stephen P. dan Timothy A. Judge, (2015), Perilaku Organisasi, Edisi 16, Jakarta: Salemba Empat, hh. 53.

Sani, Achmad. (2013). Role of procedural justice, organizational commitment and job satisfaction on job performance: the mediating effects of organizational citizenship behavior. International Journal of Business and Management. Vol. 8, No. 15. pp. 57-67

Sari, Nita Ratna., Hakam, Moehammad Soe'oed. Dan Susilo, Heru. (2015). Pengaruh Kepuasan Kerja Terhadap Turnover Intention (Studi pada AJB Bumiputera 1912 Kantor Wilayah Jatim II/Malang). Jurnal Administrasi Bisnis (JAB). Vol 27 (1).

Sesen, Harum, Basim Nejat. (2012). Impact of Satisfaction and Commitment on Teachers Organizational Citizenship. Education Psychology, 32(4). Pp: 475-491.

Stanley, Sanewe. (2013). Kepemimpinan Transformasional dan Organizational Citizenship Behavior dampaknya terhadap kinerja pegawai KPKNL Provinsi Sulawesi Utara. Jurnal EMBA. 1(3): h: 356-365. 
Sugiyono. (2013). Metode Penelitian Pendidikan (Pendekatan Kualitatif, Kuantitatif, dan $R \& D)$ ). Bandung: Alfabeta.

Supartha, Wayan Gede. (2008). Budaya Organisasi: Teori Praktis, Kasus, Dan Aplikasi Penelitian. Udayana University Press. Hal : 27.

Tania, A. dan E. M. Sutanto.(2013). Pengaruh Motivasi Kerja Dan Kepuasan Kerja Terhadap Komitmen Organisasional Karyawan Pt. Dai Knife Di Surabaya.Agora, 1(3).

Widodo, Suparno Eko. (2015). Manajemen Pengembangan Sumber Daya Manusia. Yogyakarta. Pustaka Pelajar.

Widyanto, Ribke., Jennie Suhandono Lau., Endo Wijaya Kartika. (2013). Pengaruh Kepuasan Kerja Terhadap Organizational Citizenship Behavior (OCB) Melalui Komitmen Organisasional Karyawan Cleaning Service Di Iss Surabaya. Jurnal Hospitality dan Manajemen Jasa. 1(1). hh: 36-50.

Wijaya, Ferry Jaya dan Sutanto, Eddy Madiono. (2014). Pengaruh Komitmen Organisasional Dan Kepuasan Kerja Karyawan Terhadap Organizational Citizenship Behavior (OCB) Di Pt Xyz Surabaya. AGORA. 2(2). Hh: 1-6.

Wijaya, Nina Ariani., dan Yuniawan, Ahyar. (2017). Analisis Pengaruh Budaya Organisasi Dan Dukungan Organisasi Terhadap Organizational Citizenship Behavior Dengan Komitmen Organisasi Sebagai Variabel Intervening (Studi Pada Karyawan Bagian Antaran PT. Pos Indonesia Processing Center Semarang). Diponegoro Journal of Management. Vol. 6(4). Hh: 1-15.

Xiaoming, C., and Junchen, X. (2012). A Literature Review on Organizational Culture and Corporate Performance. International Journal of Business Administration. Vol. 3(2), pp: 29-37. 